\title{
Malignant fibrous histiocytoma with diffuse spinal nerve involvement
}

\author{
R. J. KELLETT AND J. N. DEARNALEY \\ From the Department of Pathology, Nevill Hall Hospital, Abergavenny
}

SYNOPSIS Two cases of malignant fibrous histiocytoma in which paraplegia was a major feature⿹ are presented. The histological features of the tumours are discussed with particular emphasis otom the neural involvement. A brief review of the literature on the subject is included.

\section{Case 1}

Mr EN aged 64 began to experience epigastric discomfort in September 1972. When referred to hospital in December 1973 he complained of lethargy, increase in epigastric discomfort, weight loss, night sweats, and occasional vomiting. Examination showed a pale, ill-looking man with a hard epigastric mass and a palpable spleen. Laparotomy in January 1974 revealed a smooth retroperitoneal mass about $10 \mathrm{~cm}$ in diameter and 2 to $3 \mathrm{~cm}$ in thickness at the base of the transverse mesocolon. A Received for publication 2 March 1976 biopsy was taken and the frozen section was thoughie to suggest retroperitoneal fibrosis. This tentative diagnosis was again put forward when the tissue was examined after paraffin processing (fig 1). A $\overrightarrow{\vec{B}}$ intravenous pyelogram was performed and proved to be normal.

Because of the size of the mass and some doubt about the diagnosis, a course of radiotherapy wast started with subsequent shrinkage of the rego: peritoneal mass and improvement in the patie general condition.

In March 1974 an enlarged axillary lymph nôd was excised, but the histology revealed lymph nod

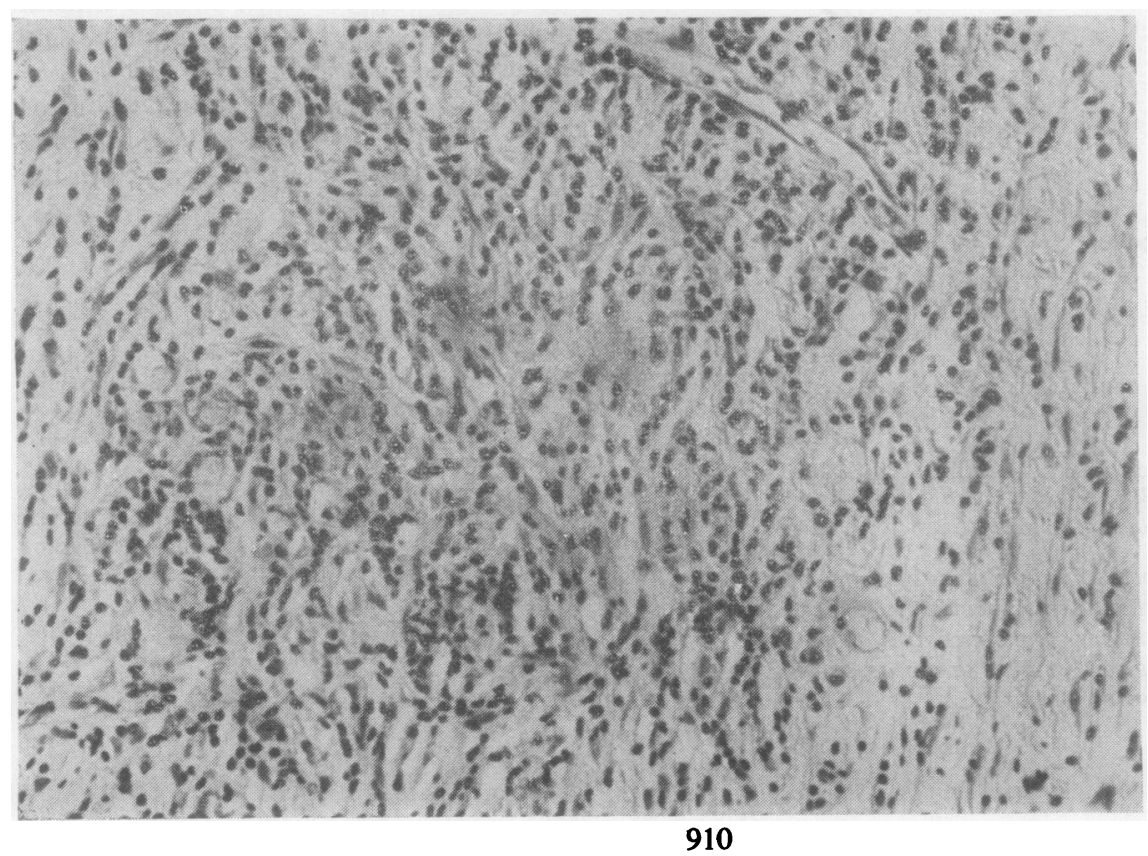

Fig 1 Case 1. Biopsy오 from retroperitoneal $>$ mass. $H$ and $E \times 120 \stackrel{\text { 을 }}{=}$ 
replaced by fat and showing no evidence of tumour. Four months later the patient developed a small subcutaneous swelling on the forehead between the eyebrows. This lesion was excised and the histological appearances proved similar to those of the retroperitoneal mass, but there was more cellular pleomorphism and mitotic activity and a storiform pattern was now discernible (fig 2). A diagnosis of malignant fibrous histiocytoma was made. Cytotoxic therapy was begun with only a slight initial improvement. By January 1975 the patient began to experience trigeminal neuralgia and some loss of sensation in the lower limbs. In about four weeks he became totally paraplegic and thereafter his condition deteriorated until his death on 1 March 1975.

Necropsy revealed a lean elderly man with a terminal bronchopneumonia. The retroperitoneal tumour had regressed, but there were nodular metastatic deposits in the liver, spleen, dorsal and lumbar vertebrae, and the meninges overlying the temporal lobes of the brain. Diffuse tumour involvement of the cranial and spinal nerves was noted. The testes were normal. Histological examination of the visceral metastases showed a similar pattern to the tumour on the forehead, but the neural involvement presented a more diffuse and unorganized histological pattern (figs 3 and 4).

\section{Case 2}

Mr BJP aged 36 first began to experience numbness and tingling in the lateral border of the left foot in October 1973. $X$-ray examination of the lumbar spine was normal and the cerebrospinal fluid showed no abnormality. His condition deteriorated and by February 1975 he was partially paraplegic and incontinent. A myelogram showed thickening of the spinal nerve roots and this was confirmed at an exploratory laminectomy when the nerve roots were seen to be markedly indurated, exhibiting a white beaded appearance. Biopsy of a nerve root was performed but no definitive diagnosis was made at this time although the material was examined by several pathologists. Tentative diagnoses included sarcoid, tuberculosis, and lymphoreticular disorder. The histological picture is illustrated in figure 5.

In April 1975 the patient was recorded to have a complete flaccid paraplegia, and in June he drew attention to his right testis which was slightly enlarged and hard. Orchidectomy was performed and the specimen submitted for examination was a testicular mass $(6 \times 4 \times 3 \mathrm{~cm})$ with a smooth outer surface. Bisection revealed that the gonad was largely replaced by a nodular, yellowish tumour of hard consistency. This proved to be a neoplasm of spindle-cell structure and storiform pattern in which occasional giant cells and small numbers of foam cells were demonstrable (figs 6 and 7). A diagnosis of malignant fibrous histiocytoma with neural involvement was made. Chemotherapy was instituted with little improvement, and at the time of writing the patient is under terminal care.

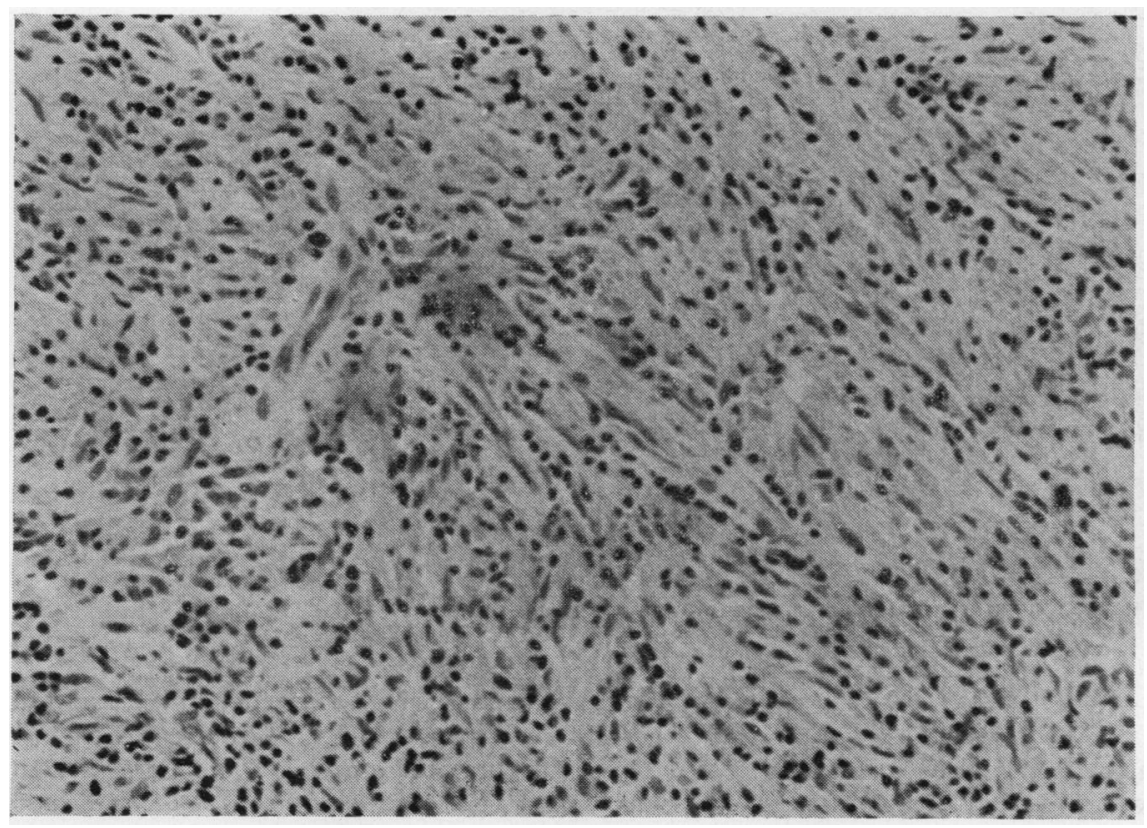

Fig 2 Case 1. Biopsy

from lesion on forehead. $H$ and $E \times 120$. 


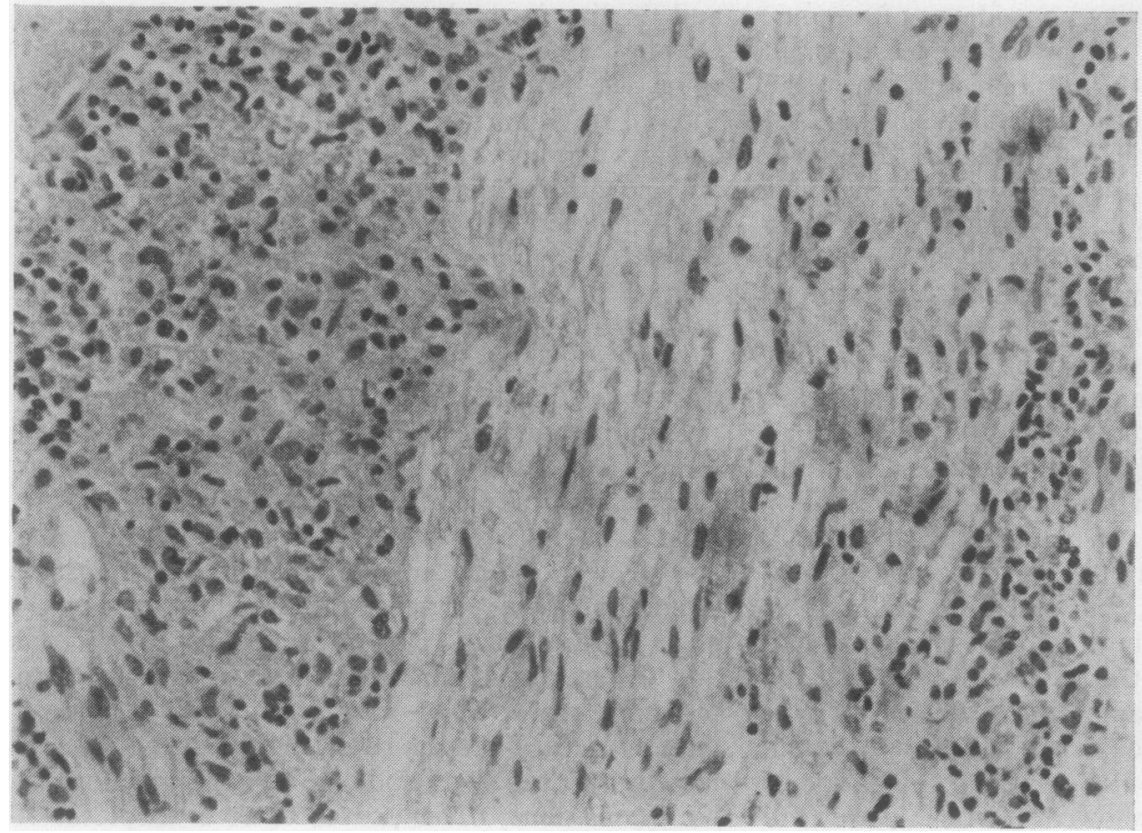

Fig 3 Case 1. Spinal $\vec{\circ}$ nerve involvement post $\overrightarrow{-}$ mortem. $H$ and $E \times 120$

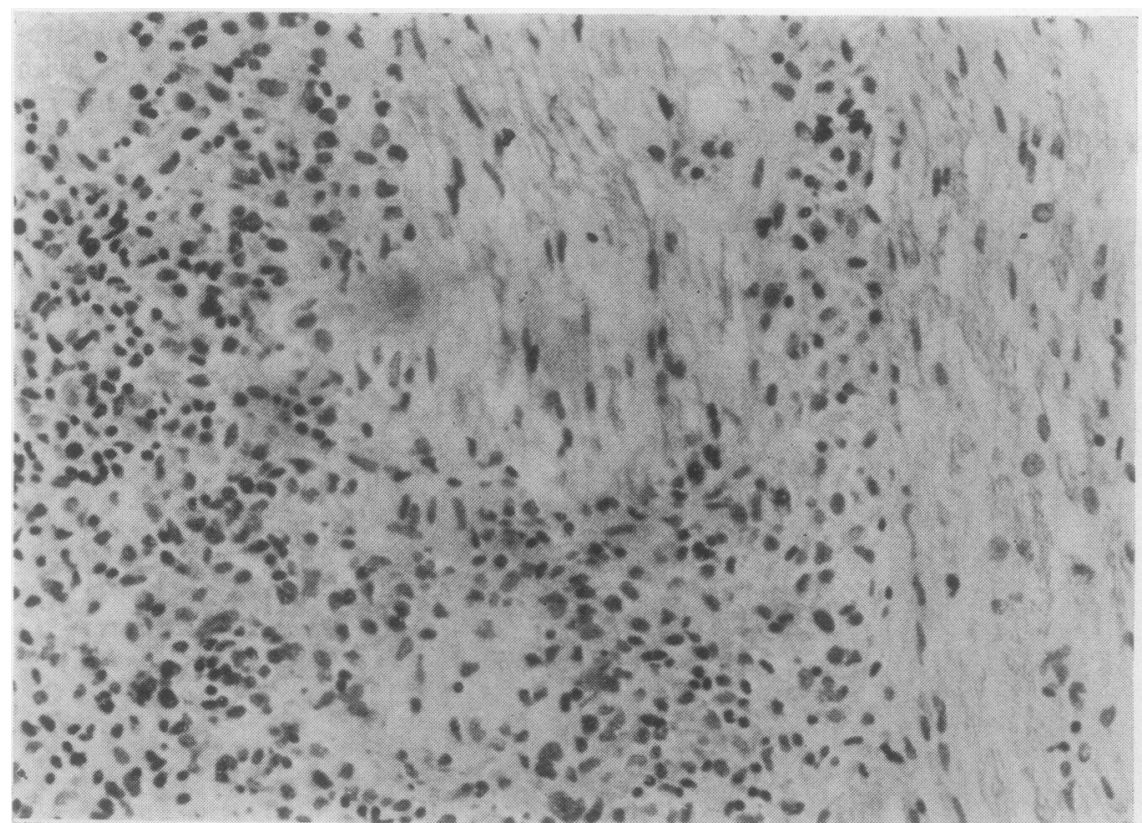

Fig 4 Case 1. Spinal nerve involvement post $\mathrm{O}$ mortem. $\mathrm{H}$ and $E \times 120$.

\section{Discussion}

In 1935 Oberling drew attention to lesions localized in the retroperitoneum which were of a granuloma- tous appearance and characterized by an abundant proliferation of histiocytic or fibrocytic elementso together with an inflammatory reaction which included foam cells and giant cells. He describe 


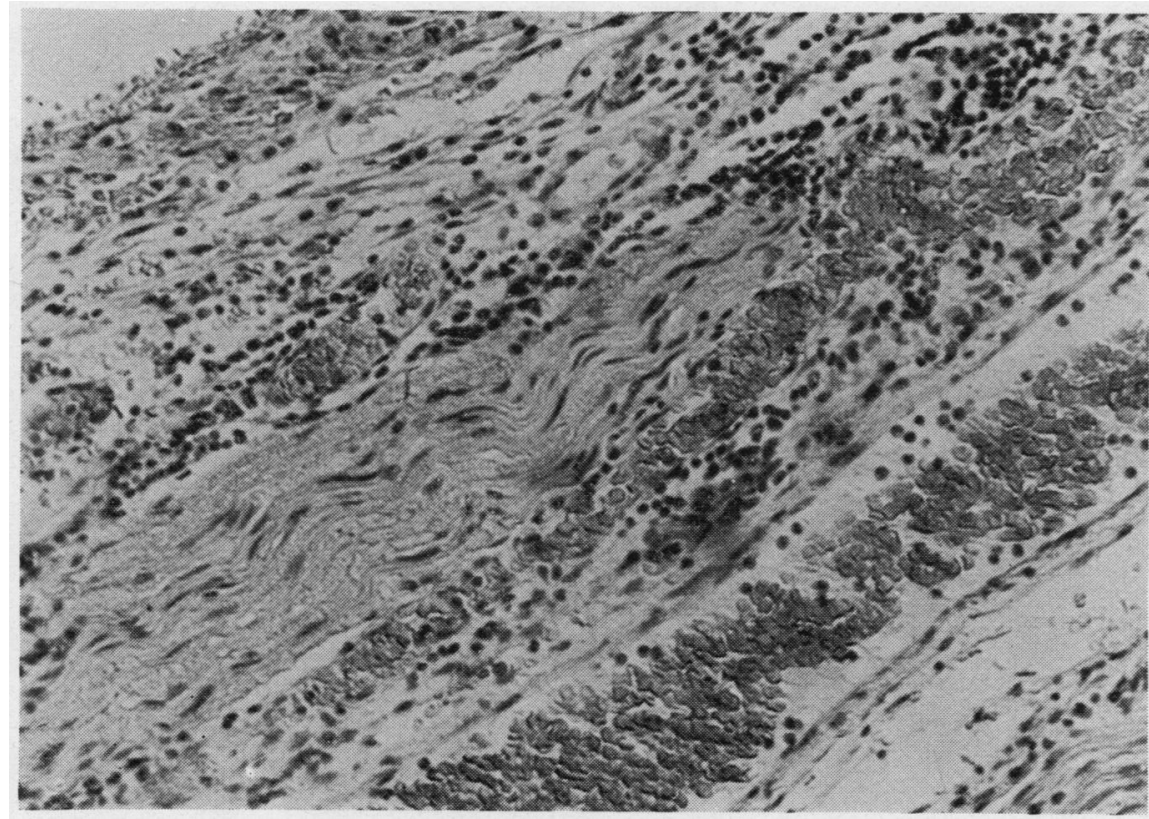

Fig 5 Case 2. Biopsy from lumbar nerve root at exploratory laminectomy. $H$ and $E \times 120$.

three such cases and reviewed the literature, reaching the conclusion that this process was a distinct pathological entity and probably represented a benign inflammatory process. He applied the term retroperitoneal xanthogranuloma to such lesions.

O'Brien and Stout (1964) reviewed 1516 tumours of possible histiocytic origin and selected 53 as probable malignant tumours. Fifteen of these they called malignant fibrous xanthomas and these were characterized by a spindle-cell morphology with a storiform or mixed pattern, and the majority of these metastasized widely.

Stout and Lattes (1967), in their discussion on malignant histiocytic tumours, stated that xanthogranulomas generally fail to metastasize but may cause death by local infiltration.

Such lesions are now generally accepted as being neoplastic rather than inflammatory, and they all may have the potential to metastasize (Kahn (1973), quoting Enzinger). The cell of origin is probably the tissue histiocyte, a concept supported by the elegant cell culture studies of Ozello et al (1963), electron microscope studies of Kahn (1973), and cell culture and electron microscope studies of Fu et al (1975).

Several series of cases of metastasizing malignant fibrous histiocytomas have been presented (RosasUribe et al, 1970; Pear, 1970; Kempson and Kyriakos, 1972; Soule and Enriquez, 1972; Wasserman and Stuard, 1974; Fu et al, 1975). Mackenzie (1975) reviewed the work of these authors and others and acknowledged the problems of nomenclature which are largely due to the ignorance of the cell of origin of the tumours. From the all-embracing group of malignant tumours of fibrohistiocytic origin he differentiated three major subgroups on histological criteria:

1 malignant fibrous histiocytoma (malignant fibroxanthoma)

2 malignant histiocytoma

3 giant-cell tumour of soft parts.

The cases that we.describe fit well into the first of these subgroups.

In both the cases we are reporting, there was involvement of the spinal nerve roots. The diffuse infiltrative character of the tumour in this situation results in some loss of specific histological features, rendering a diagnosis almost impossible should a laminectomy be performed and a biopsy taken. The nerve roots may be involved in chronic granulomatous processes, Hodgkin's disease, and other malignant lymphomas including extranodal lymphosarcoma arising primarily in the central nervous system (Rubinstein, 1972). Moreover, infiltration of the spinal meninges with extension along the perivascular spaces is now recognized as a common occurrence in acute leukaemia, and this diagnosis cannot always be excluded by a routine blood count.

Our two cases emphasize that paraplegia may be a major feature in cases of malignant fibrous histiocytoma and present a difficult diagnostic problem when no overt tumour is apparent elsewhere in the body. 


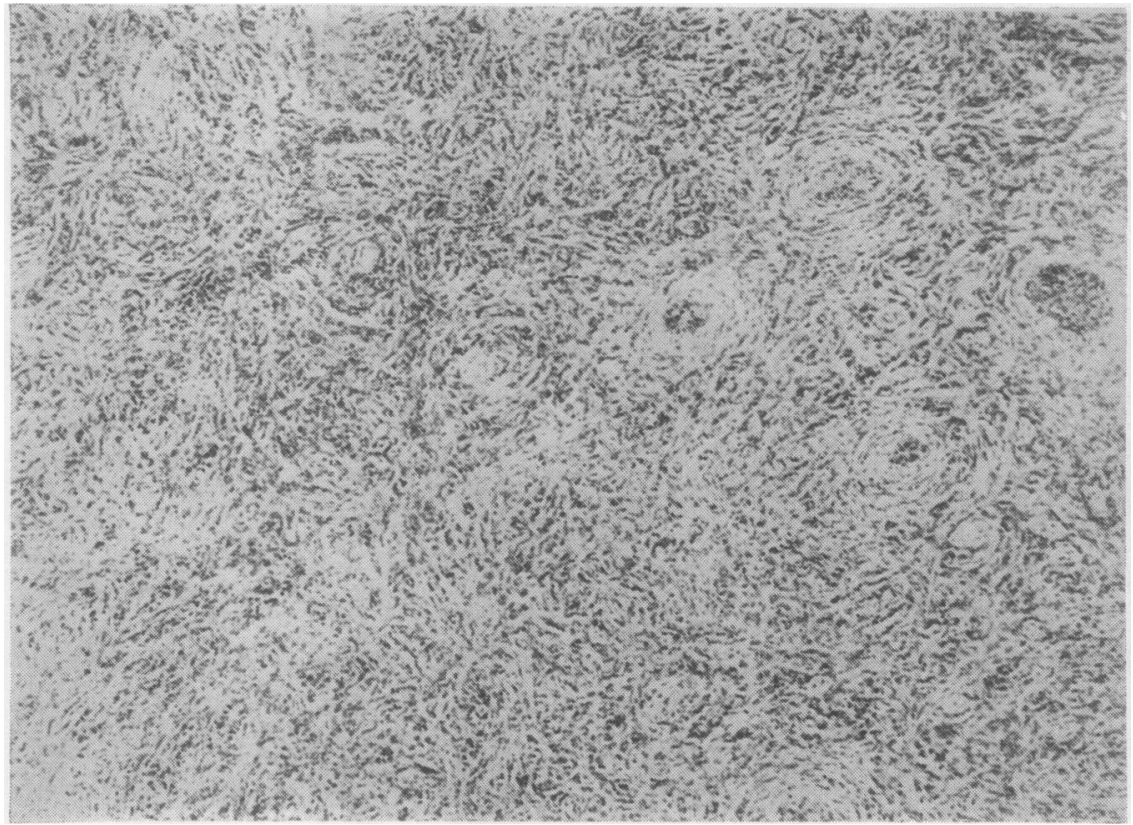

Fig 6 Case 2.

Histology of testicular $\vec{\circ}$ mass. Note the obvious $\vec{\overrightarrow{ }}$ storiform pattern of the tumour. $H$ and $E \times 12$.

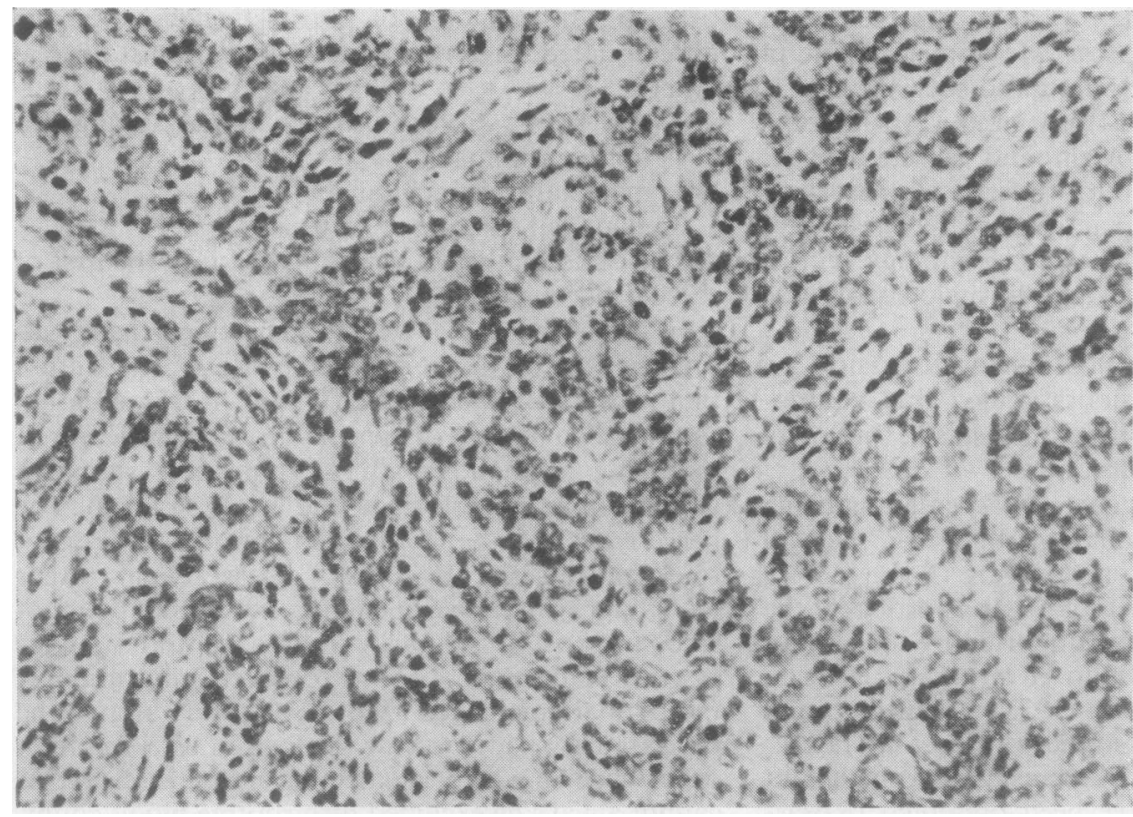

Fig 7 Case 2.

Testicular mass. $H$ and $\overline{3}$ $E \times 120$.

We are grateful to the Department of Medical Illustration, the Royal Gwent Hospital for producing the photomicrographs, to the Department of
Histology, Nevill Hall Hospital for producing theo sections, and to Mrs E. Stacey for secretarial assise tance. 


\section{References}

Fu, Y., Gabbiani, G., Kaye, G. I, and Lattes, R. (1975). Malignant soft tissue tumors of probable histiocytic origin (malignant fibrous histiocytomas): general considerations and electron microscopic and tissue culture studies. Cancer (Philad.), 35, 176-198.

Kahn, L. B. (1973). Retroperitoneal xanthogranuloma and xanthosarcoma (malignant fibrous xanthoma). Cancer (Philad.), 31, 411-422.

Kempson, R. L. and Kyriakos, M. (1972). Fibroxanthosarcoma of the soft tissues. Cancer (Philad.), 29, 961-976.

Mackenzie, D. H. (1975). Miscellaneous soft tissue sarcomas. In Recent Advances in Pathology, edited by C. V. Harrison and K. Weinbren, Churchill Livingstone Press, Edinburgh and London.

Oberling, C. (1935). Retroperitoneal xanthogranuloma. Amer. $J$. Cancer, 23, 477-489.

O'Brien, J. E. and Stout, A. P. (1964). Malignant fibrous xanthoma. Cancer (Philad.), 17, 1445-1455.

Ozello, L., Stout, A. P., and Murray, M. R. (1963). Cultural characteristics of malignant histiocytomas and fibrous xanthomas. Cancer (Philad.), 16, 331-344.

Pear, B. L. (1970). The histiocyte in radiology-with case reports of retroperitoneal xanthogranuloma and malignant fibrous xanthoma. Amer. J. Roentgenol., 110, 159-165.

Rosas-Uribe, A., Ring, A. M., and Rappaport, H. (1970). Metastasizing retroperitoneal fibroxanthoma (malignant fibroxanthoma). Cancer (Philad.), 26, 827-831.

Rubinstein, L. J. (1972). Tumours of the Central Nervous System (Atlas of Tumour Pathology, Second Series, Fascicle 6). Armed Forces Institute of Pathology, Washington, D.C.

Soule, E. H. and Enriquez, P. (1972). Atypical fibrous histiocytoma, malignant fibrous histiocytoma, malignant histiocytoma and epithelioid sarcoma. Cancer (Philad.), 30, 128-143.

Stout, A. P. and Lattes, R. (1967). Tumors of the Soft Tissues (Atlas of Tumour Pathology, Second Series, Fascicle 1), p. 107. Armed Forces Institute of Pathology, Washington, D.C.

Wasserman, T. H. and Stuard, I. D. (1974). Malignant fibrous histiocytoma with widespread metastases. Cancer (Philad.), 33, 141-146. 